\title{
Southwest Ballot Measures Affecting Healthcare
}

Modern Healthcare (1) has published an article summarizing ballot measures affecting healthcare. Those from the Southwest are listed below:

\section{Arizona}

\section{States}

1. Recreational marijuana. Proposition 205: Legalizes recreational marijuana use for people 21 and older. Opponents of the measure include the Arizona Health and Hospital Association and Insys Therapeutics, a company that makes a cannabis-based pain medication.

\section{California}

1. Medi-Cal hospital fee program. Proposition 52: Requires the legislature to get voter approval to use fee revenue for purposes other than generating federal matching funds and funding enhanced Medicaid payments and grants for hospitals. The initiative, which was written by the California Hospital Association and is supported by most state lawmakers, would also make the program permanent, requiring a supermajority in the legislature to end it.

2. Tobacco tax. Proposition 56: Increases the state's cigarette tax by $\$ 2$ a pack and impose an "equivalent increase on other tobacco products and electronic cigarettes containing nicotine." The revenue primarily would support healthcare programs.

3. Prescription drug price regulations. Proposition 61: Ties the prices California state agencies pay for prescription drugs to the discounts negotiated by the U.S. Veterans Affairs Department. The initiative, backed by the AIDS Healthcare Foundation, has drawn more than $\$ 100$ million in spending from opponents, most of it from the pharmaceutical industry.

4. Legalization of recreational marijuana. Proposition 64: Legalizes recreational marijuana use for people 21 and older and creates taxes on the cultivation and retail sale of the drug.

\section{Colorado}

1. ColoradoCare, a single-payer health system. Amendment 69: Amends the state's constitution to establish a universal healthcare system financed by payroll taxes and governed by an elected 21-member board of trustees. The plan is opposed by Colorado Hospital Association.

2. Cigarette tax. Amendment 72: Amends the state's constitution to increase the cigarette tax from 84 cents a pack to $\$ 2.59$ a pack. Most of the revenue would fund health-related programs, research into tobacco-related health issues and education and prevention. E-cigarettes are exempt. 
3. Physician-assisted suicide. Proposition 106: The End of Life Options Act allows physicians to prescribe a lethal drug to their terminally ill patients and allows terminally ill patients to be prescribed lethal drugs to end their life.

\section{Nevada}

1. Recreational marijuana. Question 2: Legalizes recreational marijuana use for people 21 and older.

2. Medical equipment tax. Question 4: Exempts medical equipment like oxygen machines and hospital beds from the state sales tax.

\section{Cities}

1. Albany, CA. Soda tax: A 1 cent per ounce tax on sugary beverages.

2. San Francisco, CA. Soda tax: A 1 cent per ounce tax on sugary beverages.

3. Oakland, CA. Soda tax: A 1 cent per ounce tax on sugary beverages.

4. Boulder, CO. Soda tax: Imposes a 2 cent per ounce tax on sugary beverages.

Richard A. Robbins, MD

Editor, SWJPCC

\section{Reference}

1. Modern Healthcare. How the Nov. 8 state elections will affect healthcare. November 5, 2016. Available at: http://www.modernhealthcare.com/article/20161105/NEWS/161109991 (accessed 11/7/16). 